
Ohr komnte dell allmählichen $A$ bfall im Lanfe des folgenden Tages auf sehr angestrengter, stridoröser Athmung, stärkster Acetongeruch im ganzen Hause. Im Laufe des 25. und 26. September liessen die comatösen Erscheinungen bis auf den starken Acetongeruch und den hohen Puls (120 bis 140) nach, um sich dann im Laufe der nächsten Tage wieder einzustellen und am 5. Oktober zum Exitus zu fïhren.

Wie schon erwähnt, wurde am 26. September der Furunkel nochmals, und jetzt bei voller Eiterung, gründlich geöffnet - wieder unter Schleich'scher Infiltration, fast oder ganz schmerzlos. Doch zeigte die Wunde von da ab keine Spur von Heilungstendenz mehr. Am 1. Oktober war die Urinmenge $8000 \mathrm{ccm}$, Zucker $7 \%$, Eiweiss in Spuren. Campher wie andere therapeutische Maassnahmen blieben wirkungslos. Hier trat also, 32 Stunden nach Inzision eines Furunkels, unter lokaler Infiltrationsanästhesie, ebenso Coma ein, wie das bei allgemeiner Narkose (Becker etc.) und auch bei Staroperationen (Hirschberg) beobachtet worden ist. $\mathrm{Ob}$ die zweite Inzision am 26. September, entschieden energischer und rücksichtsloser als die erste ausoeführt, das in spontanem Rückgang befindliche Coma roll neuem angefacht und zum letalen Ende geführt hat? Das ist wohl nicht zu entscheiden, hat aber nicht viel Wahrscheinlichkeit für sich, da das Coma diabeticum auch an und für sich Schwankungen im Verlaufe geigt. Dagegen spielen im volliegenden Falle Aufregung, Schlaflosigkeit, Nahrungsenthaltung, dazu el'zwungene Ruhelage bei psychischer äusserster Unrulue eine so grosse Rolle, dass diese allein ohne weiteres genügen, um das Coma bei einem langjährigen Diabetikel hervorzurufen.

Irgend eine „Vorbereitung“ zur Operation hatte naturgemäss niclit stattgefunden.

\title{
Aus der Praxis.
}

\section{Zum Coma diabeticum nach Operationen.}

Von Emil Sintenis, Frauenarzt im Seebad Pernau (Livland). Zur dahingehörigen Statistik möchte ich mir erlauben, einen Fall beizutragen, den ich im Herbst 1898 in Kosch (Estland) erlebte.

Hcrr v. $H$. in P. war damals 42 Jahre alt, seit neun Jahren Diabetiker, hatte bei ärztlich geregelter mässiger Diät und nach mehrfachen Kuren in Karlsbad stets Zucker im Urin in wechselnder Menge. Kurz vor der gleich $7 . u$ schildernden Episode waren es 5\% gewesen. Am 23. September 1898 wurde ich nun zu ihm gerufen, da er sich einen Furunkel zugezogen hatte. Ich fand den Patienten leicht fiebernd, sehr gequält durch einen Furunkel, der im Nacken ein Infiltrat von $8 \mathrm{~cm}$ Durchmesser gebildet hatte. Da der an sich wenig geduldige Kranke durch die Schmerzen auf das äusserste gequalt war, dazu Temperaturen vorhanden waren, schritt ich gleich zur Oeffnung des Furunkels, obgleich auf Eiter noch kaum zu rechnen war. Ich infiltrirte sehr sorgfältig nach Schleich und machte dann einen Kreuzschnitt, bei dem ich fast noch gar keinen Eiter fand. Obgleich Patient während der ganzen Manipulation arg ächzte und stöhnte, gab er mir nachher doch sofort zu, dass er gar keine Schmerzen gefühlt habe - er habe nur „zur Sicherheit" so gethan! Leider hatte er es damit aber doch auch erreicht, dass ich, gerade in Besorgniss wegen des psychischen Insultes, den Schnitt zu klein angelegt hatte. Ich glaubte, den Eingriff mö $\alpha_{-}$ lichst klein gestalten zu müssen - so wurde nach einigen Tagen eine zweite Inzision nöthig.

Gleich nach dem ersten Schnitt trat eine gewisse Erleichterung ein; die Temperatur sank von 38,3 auf 37,8 , die Eiterbildung machte unter Compressen normale Fortschritte. So sah ich den Kranken am 21 . September Abends in etwas gebessertem Zustande. Aber schon am 25. September, früh um $5 \mathrm{Uhr}$, wurde ich eiligst geholt: ich fand den Kranken in vollem Coma diabeticum! Herzschlăge 240 (mein musikgeübtes 